\section{Change in sensitivity to d-amphetamine in frontal rats as a function of time: Shifting of the dose-response curvel}

\author{
STANLEY D. GLICK, Albert Einstein \\ College of Medicine, Bronx, N.Y. 10461
}

Three doses $(0.5,1.0$, and $2.0 \mathrm{mg} / \mathrm{kg}$ ) of $d$-amphetamine and saline were administered to rats with frontal cortical ablations and to rats with sham operations during the 1st and 6th postoperative weeks. Locomotor activity of both groups of rats was measured following all injections. Hypersensitivity to d-amphetamine in the frontal rats was found to increase from the Ist to the 6th postoperative weeks.

Adler (196i) and, more recently, Lynch et al (1969) have reported that rats with frontal cortical ablations are hypersensitive to the locomotor-augmenting effect of amphetamine. However, Adler showed that frontal hypersensitivity increased with increasing time following surgery, whereas Lynch et al found frontal hypersensitivity to decrease with increasing time following surgery. Adler's rats exhibited maximal and asymptotic hypersensitivity to amphetamine by the 4 th postoperative week, whereas Lynch et al's rats exhibited almost normal sensitivity to amphetamine at that time. Both studies used the same sex and strain of rats and found similar inverted-U dose-response curves for amphetamine in normal rats. However, the two studies selected different doses of dl-amphetamine to study the time-dependent changes in frontal rats. Adler used a dose of $2.5 \mathrm{mg} / \mathrm{kg}$, whereas Lynch et al used a dose of $3.5 \mathrm{mg} / \mathrm{kg}$. Both studies interpreted increased locomotor activity to a specific dose of amphetamine as increased sensitivity to the drug. But increased drug sensitivity can imply two types of changes: (1) increasing the height of the dose-response curve, i.e., greater activity at every dose as Adler and Lynch et al assumed, and (2) shifting of the dose-response curve to the left, i.e., a lower dose in hypersensitive animals would produce the same activity as a higher dose in normal animals. The present experiment was conducted in order to determine if this second form of hypersensitivity could account for the discrepancies between the two previous studies. In particular, it was hypothesized that the time-dependent decrease in amphetamine-induced activity of the frontal rats in Lynch et al's experiment may actually have been due to increased sensitivity, i.e., if the inverted- $U$ dose-response curve shifted to the left, a dose that once produced the peak effect would later produce a lesser effect on the descending portion of the inverted $\mathbf{U}$.

\section{SUBJECTS AND SURGERY}

Sixteen naive female albino Holtzman rats, approximately 3 months old and weighing $250.270 \mathrm{~g}$, were assigned randomly to one of two groups $(\mathrm{N}=8$ in each group): frontal (F) and sham (Sh).

All surgery was conducted under Diabutal anesthesia. A scalp incision was made along the middle of the head, and subcutaneous tissue was deflected. With the use of a dental drill, bilateral burr holes, each $5 \mathrm{~mm}$ in diam, were made in the skull, $0.5 \mathrm{~mm}$ from the midline and $0.5 \mathrm{~mm}$ in front of the coronal suture. This procedure alone constituted the sham operation. Frontal cortex was removed by suction through a $20 \mathrm{-g}$ needle. Both sham and frontal operations were completed by suturing the skin with 2-0 silk.

Following their use in this experiment, all operated Ss were killed and perfused with $10 \%$ formalin; their brains were removed and immersed in $10 \%$ formalin for at least 2 months before paraffin sections were made and histological examination was conducted. In all cases, histological study showed that the major area of destruction was confined to the frontal cortex. Only rarely was subcortical white matter included in the lesion. The major area of cortex destroyed extended rostrally to the tip of the frontal pole and caudally to the genu of the corpus callosum.

\section{APPARATUS}

Four activity boxes, measuring $10^{1 / 2} \times 10 \frac{1}{2} \times 6 \frac{1}{2}$ in., were constructed out of black Plexiglas. A G.E. L14B Darlington photocell with a Tiffen infrared filter was mounted $1 \frac{1 / 4}{\mathrm{in}}$. from the floor and midway along one of the walls of each box so that the beam bisected the box. Interruption of the photocell beam therefore indicated a crossing from one side of the box to the other. Activity was recorded automatically on Sodeco counters.

\section{PROCEDURE}

On the 6th postoperative day, four pairs of rats from each group received intraperitoneal injections of saline $(0.2 \mathrm{ml})$, $0.5 \mathrm{mg} / \mathrm{kg}$ d-amphetamine, $\quad 1.0 \mathrm{mg} / \mathrm{kg}$ $\mathrm{d}-\mathrm{amphetamine,} \mathrm{or} 2.0 \mathrm{mg} / \mathrm{kg}$ d-amphetamine, respectively. Fifteen minutes after receiving its injection, each rat was placed in an activity box for $30 \mathrm{~min}$ and then returned to its home cage. This procedure was repeated on the 7 th, 8 th, and 9 th postoperative days, except that each pair of rats received a different injection on each of these days, so that activity following administration of all three doses of d-amphetamine and saline was eventually recorded for all rats. Each rat was tested in the same activity box on all 4 days and the sequence of doses was balanced for order effects.

On the 41st, 42nd, 43rd, and 44th postoperative days, the entire sequence of injections and activity measurements was repeated. Each rat was treated in exactly the way as it had been earlier.

\section{RESULTS}

Figure 1 shows the activity results of the sham and frontal rats during the 1 st (Days 6-9) and the 6th (Days 41-44) postoperative weeks. A three-way analysis of variance was performed, with operative treatment $(\mathrm{F}-\mathrm{Sh})$ as one factor, dose of d-amphetamine as another factor, and time of testing (1st-6th postoperative weeks) as the third factor. There were significant main effects of all three factors $(\mathrm{p}<.02-.01)$. The interactions between treatment and dose, between treatment and time, between time and dose, and the three-factor interaction were all significant $(p<.05-.01)$. Subsequent $t$ tests were conducted to analyze the sources of the interactions. There were no significant differences $(p>.1)$ between corresponding frontal and sham groups when injected with saline. There were also no significant ( $p>.05$ ) differences between intragroup measurements of the same animals injected during the $1 \mathrm{st}$ and 6 th postoperative weeks with saline or $2.0 \mathrm{mg} / \mathrm{kg}$ d-amphetamine. The frontal rats showed significantly $(\mathrm{p}<.02)$ greater activity than the sham rats when injected with 0.5 or $1.0 \mathrm{mg} / \mathrm{kg}$ d-amphetamine during both the $1 \mathrm{st}$ and 6 th postoperative weeks. When injected with $2.0 \mathrm{mg} / \mathrm{kg} \mathrm{d}$-amphetamine, the frontal rats were significantly $(p<.05)$ more active than the sham rats during the lst postoeprative week but not $(p>.1)$ during the 6 th postoperative week. The frontal rats, but not $(\mathrm{p}>.2)$ the sham rats, were significantly $(\mathrm{p}<.05)$ more active during the 6 th postoperative week than during the 1st postoperative week when injected with 0.5 and $1.0 \mathrm{mg} / \mathrm{kg}$ doses of d-amphetamine.

Two additional analyses of variance were conducted to determine if there were any day-to-day changes (e.g., habituation) in activity measurements during the 4 test days of the 1st and 6th postoperative weeks. There were no significant 


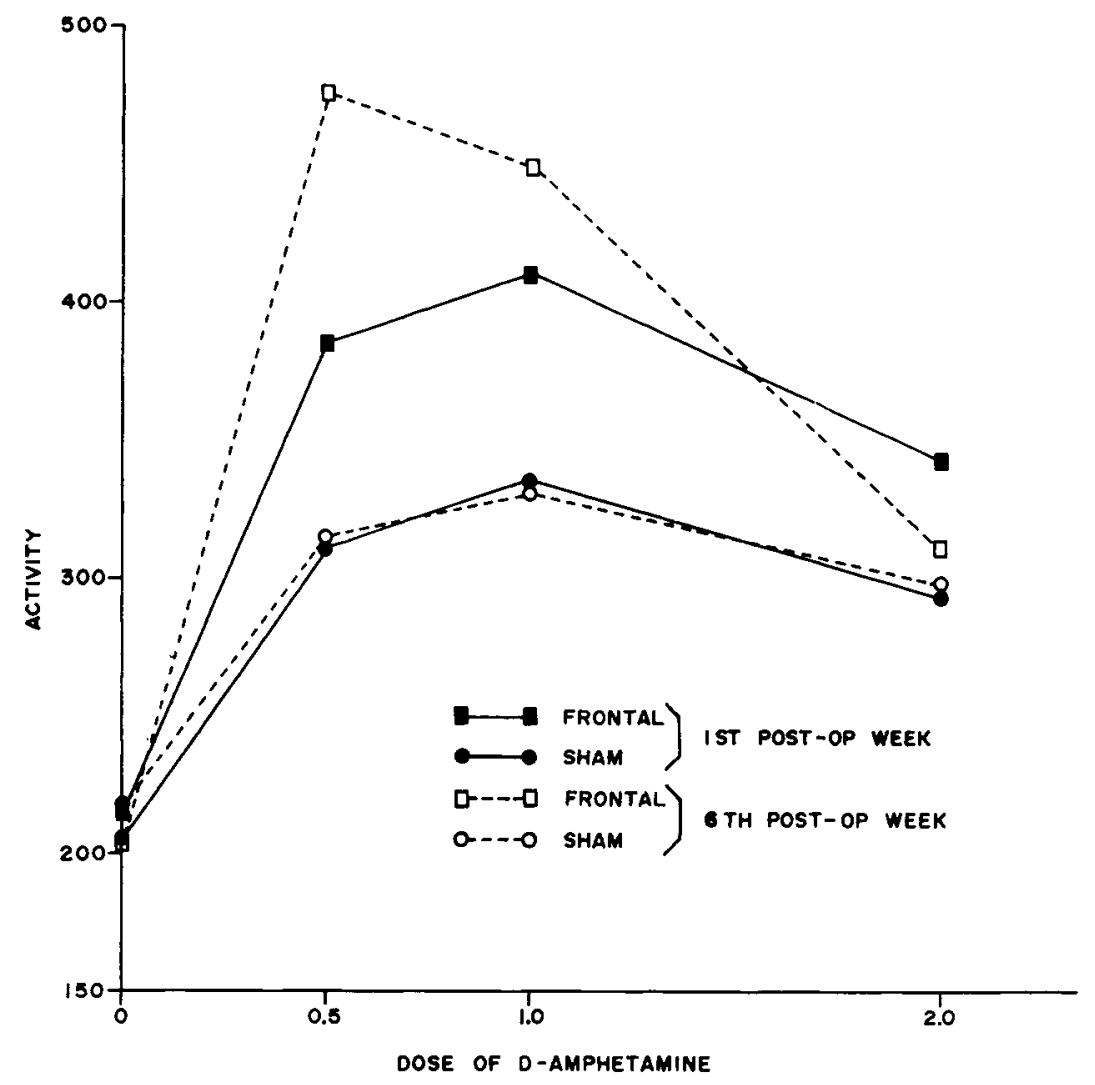

differences $(p>.2)$ among days at either postoperative time.

\section{DISCUSSION}

In agreement with both Adler (1961) and Lynch et al (1969), the frontal rats of this experiment exhibited greater activity in response to amphetamine administration a week following surgery. This occurred even though $d$-amphetamine was used instead of dl-amphetamine and female rats were used instead of male rats. As is evident in Fig. 1, the dose-response curve in frontal rats was shifted higher by the 1st postoperative week. It may also have been shifted slightly to the left, since the $2.0-\mathrm{mg} / \mathrm{kg}$ dose of d-amphetamine did not induce as large a difference betweenthe frontal and sham rats as the 0.5- and $1.0-\mathrm{mg} / \mathrm{kg}$ doses. By the 6 th postoperative week, the dose-response curve in the frontal rats was shifted even higher and data.
Fig. 1. Activity (photocell counts) as a function of dose of d-amphetamine ( $\mathrm{mg} / \mathrm{kg}$ ) in frontal and sham rats during the 1 st and 6 th postoperative weeks.

support the conclusion that hypersensitivity to amphetamine following frontal ablations increases with increasing time following surgery, an explanation for the contradictory findings of Lynch et al is not completely apparent. Increasing hypersensitivity in this experiment was evidenced more by the shifting higher of the dose-response curve than by its shifting to the left; the activity response of frontal rats to the peak dose of the lst postoperative week did not decrease with increasing time, but increased. Of course the use of d-amphetamine instead of dl-amphetamine and of female rats instead of male rats could have altered the type and/or the rate of the time-dependent changes. Other methodological factors ${ }^{2}$ might also have been influential, e.g., the level of baseline activity preceding amphetamine administration. Lynch et al's rats were placed in the activity apparatus 2 days prior to amphetamine injections and were completely habituated to the apparatus at that time. Adler's rats and the rats in this experiment were placed in their activity apparatuses for only a short time following injections.

more to the left: the $0.5-$ and $1.0-\mathrm{mg} / \mathrm{kg}$ doses elicited even greater activity, whereas activity elicited by the $2.0-\mathrm{mg} / \mathrm{kg}$ dose was somewhat decreased. The most interesting result of this experiment was the response of the frontal rats to this latter dose: Their activity following injection of $2.0 \mathrm{mg} / \mathrm{kg}$ d-amphetamine during the $6 \mathrm{th}$ postoperative week was not significantly different from the respective activity of the sham rats. If a more complete dose-response curve had not been done, it might have been concluded that sensitivity of the frontal rats to d-amphetamine had recovered to normal. The response of the frontal rats to the $0.5-$ and $1.0-\mathrm{mg} / \mathrm{kg}$ doses, however, clearly indicated that hypersensitivity was maintained. Adler's findings, rather than those of Lynch et al, are therefore supported by the present

Although the results of this experiment

\section{REFERENCES}

ADLER, M. W. Changes in sensitivity to amphetamine in rats with chronic brain lesions. Journal of Pharmacology \& Experimental Therapeutics, 1961, 134 214-221.

LYNCH, G. S., BALLANTINE, P., \& CAMPBELL, B. A. Potentiation of behavioral arousal after cortical damage and subsequent recovery. Experimental Neurology, 1969, 23 , 195-206.

\section{NOTES} from NIH 5T5 GM1674 and by a USPHS grant, NIMH-05319, to M. E. Jarvik. The author wishes to thank M. E. Jarvik for his encouragement during the research and for his critical reading of the manuscript

2. Lesion size might also be a source of contradiction. As far as the author could determine, Adler's lesions were larger than those of Lynch et al. The lesions of the rats in this experiment appeared to be smaller than those of Adler but larger than those of Lynch et al.
1. Supported by a postdoctoral fellowship 